\title{
Causes of ischaemic stroke in the young
}

\author{
PJ Martin, TP Enevoldson, PRD Humphrey
}

\begin{abstract}
Summary
The causes of ischaemic stroke in young adults are many and diverse. Such patients usually require more extensive investigations in order to find an underlying cause than more elderly patients. It is important that a comprehensive search is made since many of the underlying disorders are treatable. Principal causes are extracranial arterial dissection, cardioembolism, premature atherosclerosis, haematological and immunological disorders and migraine. Drug abuse is becoming increasingly important but the risk of stroke in pregnancy remains unclear. Isolated angiitis of the central nervous system, heritable disorders of connective tissue and other genetically determined disorders (mitochondrial cytopathies, CADASIL) account for a small proportion of ischaemic strokes in the young. Management is probably best undertaken by a physician with a specialist interest and, if full investigation fails to elucidate a definite cause, the risk of future stoke is low
\end{abstract}

Keywords: ischaemic stroke, cerebral infarction, young adult

\author{
Department of Neurology, Walton \\ Centre for Neurology and \\ Neurosurgery, Rice Lane, Liverpool \\ L91AE, UK \\ PJ Martin \\ TP Enevoldson \\ PRD Humphrey
}

Accepted 7 February 1996
Stroke is the third most common cause of mortality in Westernised countries and accounts for $12 \%$ of all deaths in the UK. The economic cost of stroke is enormous - approximately $4-5 \%$ of the annual National Health Service budget. ${ }^{1}$ Twelve per cent of first strokes occur in patients under 45 years of age, ${ }^{2}$ of which approximately $50 \%$ are ischaemic in nature (cerebral haemorrhage is relatively over-represented in this age group compared to the elderly).

Reported incidence rates of ischaemic stroke in the young vary according to study design and population structure. The annual incidence of young stroke in the UK has been estimated at approximately 10 per 100000 (female:male, $1.6: 1)^{3}$ in a prospective, community-based study. Other Western European studies have provided crude incidence rates up to three times higher. ${ }^{4-6}$

Most reports of young stroke apply an age limit of 45 years to the study population. Over this age, incidence rises sharply and the spectrum of underlying causes narrows as atherosclerosis becomes increasingly prevalent. Whereas degenerative atherosclerotic disease and cardioembolism account for most ischaemic strokes in the elderly, cerebral infarction in younger age groups may be the presenting feature of a diverse range of local and systemic diseases. Full evaluation of the young patient is likely to elucidate an underlying cause, many of which are treatable. The management of young stroke therefore requires a modified approach, encompassing initial investigation and treatment, as well as advice on prognosis and counselling for the devastating psychological consequences.

\section{The clinical encounter}

No matter which classification of stroke syndrome the clinician chooses to use, the clinical picture will reflect the anatomical distribution of brain damage and will, with occasional exceptions, mirror the stroke syndromes seen in the elderly. In history taking, it is important to enquire specifically about previous deep vein or pulmonary thromboses (coagulopathies), arthralgia (systemic lupus), skin rashes (vasculitis, antiphospholipid syndrome, Fabry's disease), miscarriages (antiphospholipid syndrome), a family history of thromboses (inherited thrombophilias), or drug abuse. The clinician must also be clear about the nature of onset of the neurological deficit. It is not uncommon for multiple sclerosis to cause an isolated hemiparesis which may be wrongly attributed to vascular disease. However a hemiparesis due to demyelination usually develops over at least $24-48$ hours rather than abruptly, and is often partial rather than complete as in most vascular events.

The clinical examination will focus on the nervous and cardiovascular systems. The presence and equality of all peripheral pulses must be sought (coarctation, subclavian stenosis, Takayasu's arteritis). Auscultation of the heart should be followed by a search for carotid and subclavian bruits although the presence of the former shows poor accuracy in predicting a significant carotid stenosis. ${ }^{7}$ The cutaneous stigmata of hyperlipidaemias are usually readily apparent. Other features such as a Horner's syndrome (carotid dissection), Marfanoid habitus (Marfan's syndrome, homocystinuria), skin laxity and joint hypermobility (Ehlers-Danlos, pseudoxanthoma elasticum), livedo reticularis (Sneddon's syndrome), vasculitic rash, splinter haemorrhages, oral and genital ulcers (Behcet's) and venepuncture marks should not be overlooked.

Fundoscopy can provide important clues: papilloedema (cerebral venous thrombosis), Roth spots (subacute bacterial endocarditis), optic atrophy and retinitis pigmentosa (mitochondrial cytopathy), cholesterol emboli (carotid stenosis) and signs of vasculitis (attenuated vessels, retinal haemorrhages, cotton wool spots, etc).

\section{Investigacions}

Is the stroke 'arterial' or 'venous'? Venous infarction arises from thrombosis of the dural sinuses and cortical veins. It is usually haemorrhagic with symptoms evolving over several days; headache, papilloedema, seizures and a fluctuating 


\section{Commonly performed investigations in young stroke patients}

General

- full blood count

- erythrocyte sedimentation rate

- biocemichistry screen

- glucose

- cholesterol and triglycerides

- electrogardiogram

- chest radiograph

- CT brain scan

\section{Specific}

- clotting profile

- proteins C \& S, antithrombin III

- haemoglobin electrophoresis

- lupus anticoagulant

- anticardiolipin antibodies

- antinuclear antibodies and dsDNA antibodies

- VDRL/TPHA

- HIV

- urine drug screen

- urine homocysteine/nitroprusside test

- methionine loading test

- muscle biopsy

- DNA analysis

- cerebrospinal fluid analysis

- transthoracic echocardiography

- transoesophageal echocardiography

- carotid/vertebral artery ultrasound

- MRI scan (brain and neck)

- MRA intra- and extracranial arteries

- intra-arterial carotid/vertebral angiography

- leptomeningeal and brain biopsy

Box 1 neurological deficit with depression of consciousness are common. Cerebral venous thrombosis has been reviewed previously. ${ }^{8}$ Which and how many arterial territories are involved? Infarction in multiple arterial territories often indicates a cardioembolic source, or the presence of a more diffuse process such as an arteritis. If there has been only one event, it is impossible to differentiate a peripheral from a cardiac source unless there are other clinical clues. However, multiple events within the same arterial territory should focus initial attention on the supplying vessel.

As technology progresses, so the range of diagnostic tests available increases (box 1). Rather than subject each patient to investigations as part of a routine work-up it would seem better practice to tailor the investigations according to clinical pointers. Thus a patient with splinter haemorrhages and a cardiac murmur requires blood cultures and echocardiography whereas a patient with hemicranial pain and a Horner's syndrome requires assessment of the carotid arteries to exclude dissection.

\section{THE BRAIN}

All young patients with stroke require at least a cranial computed tomography (CT) scan in order to exclude primary intracerebral or subarachnoid haemorrhage. CT should confirm the site of the infarct, although it may be normal within the first 24 hours of stroke onset. After the clinical encounter, CT, or preferably magnetic resonance imaging (MRI), is the next guide in determining whether future tests should concentrate on a given arterial territory, a cardiac cause or a systemic cause. Haemorrhagic transformation occurs commonly in cardiac embolism and venous infarcts, and multiple deep white matter infarcts are more likely to represent a systemic disorder.

The greater availability of CT compared to MRI dictates that the former will be performed first in most cases of young stroke. Although MRI better delineates areas of infarction in the acute phase, it is relatively poor at demonstrating acute parenchymal or intraventricular haemorrhage. If there is doubt about whether the CT lesion is due to infarction, MRI will often distinguish other pathologies. However, interpretation of small high signal lesions seen on $\mathrm{T} 2$ and proton density weighted scans requires care since these appearances can result from small vessel ischaemia (hypertension, arteritis) or demyelination. The latter pathology is suggested by a characteristic periventricular distribution, or the presence of similar lesions in the brainstem and cerebellar peduncles. MRI is the modality of choice for imaging lacunar, brainstem and posterior fossa infarcts. It is more likely than CT to show small subclinical infarcts.

\section{THE HEART}

Standard 12-lead electrocardiography and chest radiography are required. Unless it is certain that the cause of stroke lies outside the heart, transthoracic echocardiography (TTE) is indicated, although its yield in the absence of clinical signs is low. ${ }^{9}$ TTE provides an indication of left atrial and ventricular size and function plus a guide to the morphology and function of the mitral and aortic valves. Valvular vegetations may be imaged as may left ventricular mural thrombus. However, left atrial and a significant proportion of left ventricular thrombi will be missed - although clues such as dyskinetic segments or left atrial enlargement may suffice for the clinical decision to anticoagulate. TTE, like all ultrasound techniques, is operator and patient dependent, and because pathology is not demonstrable does not mean that it does not exist.

Although large atrial septal defects may be imaged by TTE, small defects such as patent foramen ovale are easily missed. The introduction of bubble contrast $(5-10 \mathrm{ml}$ of agitated saline or water) via a peripheral vein aids the detection of patent foramen ovale since bubbles appear to travel from the right to left atrium during the Valsalva manoeuvre in the presence of a right to left shunt. A similar technique can be used during transoesophageal echocardiography (TOE) which is the imaging modality of choice for imaging the aortic root, atria, and inter-atrial septum. Atrial septal aneurysms, patent foramen ovale, left atrial appendage thrombi and valvular vegetations are all more clearly visualised using TOE. In deciding to use TOE, the clinician must weigh the expected diagnostic yield against the availability and semi-invasive nature of the technique. It seems reasonable to proceed to TOE if TTE were technically unsatisfactory in demonstrating the cause of an abnormal clinical finding, if TTE shows a lesion which requires further characterisation, or if a careful search elsewhere has failed to elucidate an embolic source. ${ }^{10}$ 


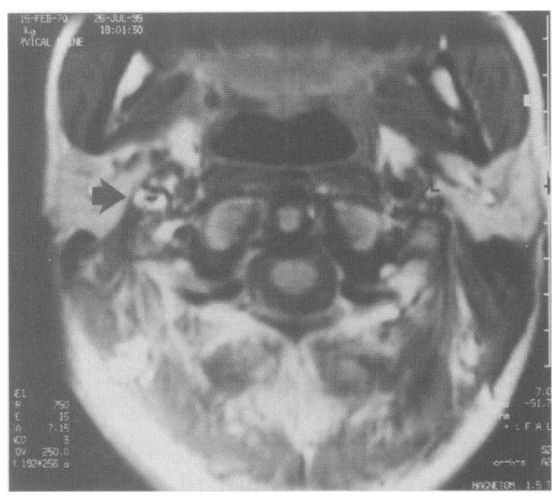

Figure 1 Axial T1 weighted magnetic resonance image through the neck. The wall of the right common carotid artery shows an area of high signal within, representing haemorrhage in a dissecting false lumen (bold arrow). The left common carotid artery shows a normal flow void (open arrow)

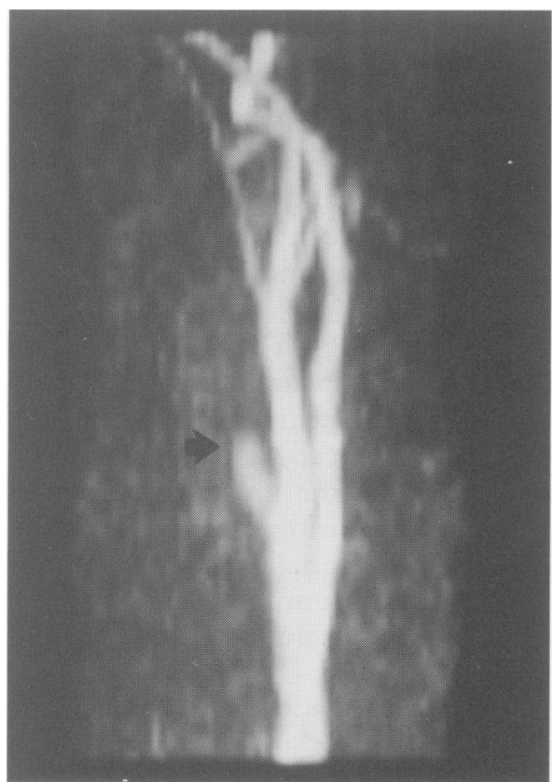

Figure 2 MRA of the cervical carotid and vertebral arteries (Case 1). The left internal carotid arery is completely occluded with a small stump remaining at its origin (arrow)
THE EXTRACRANIAL VESSELS

Ultrasound scanning is the screening modality of choice for the detection of extracranial carotid or vertebral artery disease. Modern systems provide high resolution grey-scale images of the carotid bifurcation, show the column of flowing blood by colour-coded ultrasound and estimate blood flow velocities using the Doppler principle. Examination is entirely noninvasive but is highly operator dependent. The technique shows high accuracy in the detection of moderate and severe stenosis of the carotid arteries but the differentiation of very high grade stenosis from complete occlusion can be difficult. Carotid ultrasound can demonstrate carotid artery dissection - either directly by Bmode imaging of a dissection flap, or by demonstrating the typical to and fro signal of blood oscillating within the residual internal carotid artery stump. ${ }^{11}$

It is our policy to confirm ultrasound detected abnormalities using MRI and magnetic resonance angiography (MRA). MRA shows high sensitivity and specificity for the detection of carotid stenosis when compared against intraarterial angiography. ${ }^{12}$ Standard T1 weighted axial MRI sequences through the neck demonstrate the presence of fresh thrombus (appearing as high intensity signal) within the arterial wall following dissection of the carotid or vertebral arteries (figure 1). ${ }^{11}$ In carotid dissection, MRA demonstrates the typical tapering internal carotid artery stump (figure 2) and may show a 'string sign' indicating a narrow residual lumen. This sign is also seen with very high grade stenosis or pseudo-occlusion. The physiological asymmetry of the vertebral arteries makes noninvasive diagnosis of vertebral dissection more difficult on ultrasound and MRA but the demonstration of high signal within the vessel wall on axial MRI sequences enables confident diagnosis.

Intra-arterial digital subtraction angiography carries a $1 \%$ overall risk of serious morbidity or mortality. We reserve it for those patients in whom the above techniques have failed to demonstrate adequately the suspected pathology, and for patients too claustrophobic to tolerate MR scanning. We only perform angiography if it has a high chance of yielding useful diagnostic data with implications for acute management, secondary prevention, or sometimes prognosis. In general, each angiographic study should be limited to the culprit arterial territory in order to minimise potential complications. ${ }^{13}$ Angiography demonstrates occlusive disease due to atheroma or Takayasu's arteritis, carotid dissection (string-sign), fibromuscular dysplasia (beading of the vessel wall), intracranial vasculitis (segmental narrowing and tapering of medium and small arteries) in 50\% of cases, and the 'puff of smoke' characteristic of moya-moya disease.

\section{THE INTRACRANIAL VESSELS}

The intracranial vessels can be imaged noninvasively using MRA. Limitations in spatial resolution dictate that smaller vessels are less well imaged. MRA can demonstrate intracranial arterial occlusion, stenosis, arteriovenous malformations and aneurysms of over $5 \mathrm{~mm}$ diameter. ${ }^{14}$ Diseases of smaller vessels such as arteritis can be detected, although intra-arterial angiography remains the modality of choice. ${ }^{15}$

Transcranial Doppler ultrasound is able to provide a measure of intracranial artery blood flow velocity (usually limited to the middle cerebral artery). Intracranial artery stenosis and occlusion can be detected, and the cheap and portable nature of transcranial Doppler ultrasound makes it a potentially useful bedside monitoring technique, especially for monitoring arterial recanalisation. ${ }^{16}$ Transcranial Doppler ultrasound is able to detect microembolic phenomena ${ }^{17}$ and the registration of such signals in the cerebral circulation in response to a peripheral venous injection of echo-contrast agents is an indicator of right to left shunting in patients with atrial septal defects or patent foramen ovale. ${ }^{18}$

\section{Principal causes}

\section{DISSECTION OF THE EXTRACRANIAL ARTERIES}

Dissection of the carotid or vertebral arteries is associated with disorders of connective tissue such as Ehlers-Danlos syndrome, Marfan's syndrome, pseudoxanthoma elasticum, fibromuscular dysplasia and cystic medial degeneration. There is an association with intracranial aneurysms and possibly with alpha-1-antitrypsin deficiency. ${ }^{19}$ An underlying disorder is apparent in a small minority of cases. Dissection can be either spontaneous or post-traumatic but the provoking event can be trivial, thus blurring this distinction. Reported causes include whiplash injuries, cervical manipulation by chiropractors, abrupt changes in posture, skiing, swimming and seizures.

The incidence of spontaneous carotid dissection is similar to that of subarachnoid haemorrhage-approximately $2.5-3$ per 100000 per year. ${ }^{20}$ 


\begin{tabular}{|c|}
\hline $\begin{array}{l}\text { Principal causes of ischaemic } \\
\text { stroke in young adults }\end{array}$ \\
\hline $\begin{array}{l}\text { Large artery disease } \\
\text { - premature atherosclerosis } \\
\text { - carotid and vertebral dissection } \\
\text { - fibromuscular dysplasia } \\
\text { - radiotherapy } \\
\text { - homocystinuria } \\
\text { - Moya-moya disease } \\
\text { - Takayasu's arteritis }\end{array}$ \\
\hline $\begin{array}{l}\text { Small artery disease } \\
\text { - hypertension associated } \\
\text { vasculopathy } \\
\text { - migraine }\end{array}$ \\
\hline $\begin{array}{l}\text { Cardioembolism } \\
\text { - valvular heart disease including } \\
\text { - mitral valve prolapse } \\
\text { - prosthetic heart valves } \\
\text { - atrial fibrillation } \\
\text { - acute myocardial infarction } \\
\text { - left ventricular dyskinaesia/aneurysm } \\
\text { - left atrial aneurysm } \\
\text { - dilated cardiomyopathy } \\
\text { - atrial septal defect including patent } \\
\text { - foramen ovale } \\
\text { - bacterial endocarditis } \\
\text { - Libmann Sachs endocarditis } \\
\text { - atrial myxoma }\end{array}$ \\
\hline $\begin{array}{l}\text { Thrombophilias } \\
\text { - protein C and S deficiency } \\
\text { - antithrombin deficiency } \\
\text { - hyperfibrinogenaemia } \\
\text { - myeloproliferative syndromes } \\
\text { - hyperviscosity syndromes } \\
\text { - antiphospholipid syndromes } \\
\text { - sickle cell disease }\end{array}$ \\
\hline $\begin{array}{l}\text { Vasculitides } \\
\text { - drug abuse } \\
\text { - cerebral lupus } \\
\text { - polyarteritis nodosa } \\
\text { - Wegener's granulomatosis } \\
\text { - sarcoidosis } \\
\text { - Behcet's syndrome } \\
\text { - isolated angiitis of the nervous } \\
\text { - } \text { - Zostem arteritis }\end{array}$ \\
\hline Pregnancy \\
\hline $\begin{array}{l}\text { Genetic } \\
\text { - CADASIL } \\
\text { - MELAS } \\
\text { - heritable disorders of connective } \\
\text { tissue } \\
\text { - Fabry's disease }\end{array}$ \\
\hline Venous infarction \\
\hline
\end{tabular}

Box 2
Carotid dissection accounts for $10-25 \%$ of stroke in the 15-45 year age group. ${ }^{21,22}$ Its recognition has important management implications. Carotid dissection presents with local and/or ischaemic symptoms. Local symptoms are neck or hemicranial pain (75\% of patients), sometimes accompanied by an ipsilateral Horner's syndrome (35\% of patients) due to stretching of the sympathetic fibres surrounding the internal carotid artery. Sweating of the face is usually preserved since these fibres accompany the external carotid artery. Rarely a carotid aneurysm may develop but these virtually never rupture. Lower cranial nerve palsies (XII, IX, X, in order of frequency) and rarely third nerve palsies are recognised. Isolated headache and pulsatile tinnitus are unusual.

Local symptoms are followed in $60-75 \%$ of patients by transient ischaemic attacks or completed stroke due to distal embolisation from the thrombosing false lumen. ${ }^{23,24}$ Dissection of the vertebral artery commonly provokes neck pain together with ischaemic symptoms referable to the posterior circulation. Unlike carotid dissections, vertebral dissections more frequently originate or extend intracranially and blood may enter the subarachnoid space causing meningism. A minority of patients $(<30 \%)$ have simultaneous dissections of two or more vessels - in these patients a careful search for an underlying connective tissue disorder is necessary.

Dissection of the extracranial vessels is confirmed by duplex ultrasound, MRI, MRA or angiography. ${ }^{1,25,26}$ Management depends upon the presence or absence of neurological episodes and the timing of the initial event. Ischaemic events commonly occur within the first week of the dissection, but can arise up to one month afterwards. ${ }^{23}$ In most patients presenting acutely who have had ischaemic episodes in the carotid territory, it is our policy to anticoagulate with intravenous heparin, followed by warfarin for six months. ${ }^{23,25,27}$ Anticoagulation is also used in extracranial vertebral artery dissection accompanied by ischaemic events ${ }^{28}$ but we advise prior lumbar puncture to exclude subarachnoid extension. In extensive cerebral infarction the risk of haemorrhagic transformation might preclude early anticoagulation. Patients presenting late or with local symptoms alone can be managed safely with $300 \mathrm{mg}$ of aspirin daily. Patients falling between these extremes must be judged in their own right and the risks and benefits of anticoagulation considered. Unfortunately, there are no good trial data to help.

Many dissected arteries recanalise within three to six months, and no surgical procedure (eg, thrombectomy, endarterectomy) is necessary. Assuming there is no underlying connective tissue disorder, the risk of recurrence is lowapproximately $1 \%$ per annum. ${ }^{24}$

\section{CARDIOGENIC EMBOLISM}

A cardiac source of emboli is found in $20-30 \%$ of young stroke patients. ${ }^{22,29}$ The most common cardiac lesions are prosthetic heart valves, rheumatic valve disease, bacterial endocarditis, dilated cardiomyopathy, ischaemic dyskinetic segments, atrial septal aneurysm, patent foramen ovale, and mitral valve prolapse. $^{30}$ The causative associations of the last three conditions are unclear. Both patent foramen ovale and mitral valve prolapse occur frequently in normal young adult populations (in up to $30 \%$ and up to $20 \%$,respectively). ${ }^{31-34}$ These lesions are frequent isolated findings $(40 \%$ and $10 \%$, respectively) in series of young stroke and occur four times as commonly in such patients as in age- and sex-matched controls. ${ }^{30-33,35}$ Mitral valve prolapse seems likelier to be the culprit if there is significant ( $>2 \mathrm{~mm}$ ) prolapse of one or both valve leaflets and if there is accompanying myxomatous degeneration. ${ }^{36}$ The latter predisposes to both infective endocarditis and to the formation of noninfective thrombotic vegetations. Overall, patients with mitral valve prolapse have a risk of stroke of only 1 in 6000 per year, ${ }^{37}$ thus it is advisable to exclude other causes of stroke first.

Atrial septal aneurysm is a lax segment of the interatrial septum whose presence frequently indicates the coexistence of a patent foramen ovale. It is unclear whether atrial septal aneurysm is an independent cause of embolic stroke or whether it indicates the presence of more extensive septal defects likely to permit right to left interatrial shunting. ${ }^{38,39}$ Right to left shunting is not always demonstrable in limited patent foramen ovale defects and most strokes do not originate during manoeuvres (eg, Valsalva) which increase right atrial pressures.

Spontaneous echo contrast is a frequent finding on transoesophageal echocardiography in young stroke patients (up to $9 \%$ ). ${ }^{40}$ It is caused by sluggish left atrial blood flow and is more common in atrial fibrillation. The significance of this finding is unclear but it may indicate flow disturbance within the left atrium sufficient to allow thrombus formation. The growing availability of transoesophageal echocardiography and its sensitivity in picking up subtle 


\section{Case report 1: Internal carotid artery dissection}

A 35-year-old woman suffered minor left-sided neck pain triggered by sudden braking of a coach. Ten days later she had an episode of left amaurosis followed several hour later by transient dysphasia, right-sided facial weakness and right hand clumsiness. She attended the local hospital and emergency CT of the brain was normal. As her symptoms had improved she was discharged. Two weeks later the only signs were mild drooping of the right corner of the mouth and mild clumsiness of the right hand. An urgent MRI of the brain showed three discrete left frontoparietal infarcts, one of which showed haemorrhagic transformation. MRA of the cervical carotid arteries showed occlusion of the left internal carotid artery with a small residual stump (figure 2). Axial T1-weighted images of the neck showed high signal within the wall of the left internal carotid artery with complete obliteration of the true lumen. These appearances were consistent with a left internal carotid artery dissection with cerebral embolism from the thrombosed vessel. The dissection had presumably been precipitated by relatively trivial neck trauma. Aspirin $300 \mathrm{mg}$ daily was commenced and she suffered no further neurological episodes. abnormalities whose prevalence in asymptomatic subjects is unknown, creates a dilemma in deciding whether such abnormalities are causative.

The identification of a cardiac lesion requires appropriately targeted medical or surgical management. The risk of further cardioembolic phenomena is high immediately after the first event, thus secondary prevention should be instituted with warfarin. This can be commenced immediately if the initial deficit or ischaemic lesion is small. Larger infarcts carry a greater risk of haemorrhagic transformation but after 11 days the risk is low-therefore a delay in anticoagulation of these patients is prudent. ${ }^{41}$

\section{PREMATURE ATHEROSCLEROSIS}

When the causes of stroke in the young are broken down by age, atherosclerosis becomes increasingly prominent from the $15-30$ year age group (2\%) to the $30-45$ year group $(30-35 \%) .^{32,42}$ In addition to the usual risk factors (hypertension, cigarette smoking, hyperlipidaemia, diabetes mellitus), premature atherosclerosis has less widely recognised associations.

Patients with homocystinuria (an autosomal recessive inability to convert homocysteine to cystathionine and methionine) develop premature large vessel atherosclerosis. Homozygotes have Marfanoid features and diagnosis is confirmed by finding elevated homocysteine levels in blood and urine and a positive nitroprusside test. Heterozygotes and patients with milder hyperhomocysteinaemia also have a tendency to premature atherosclerosis. ${ }^{4-45} \mathrm{~A}$ methionine loading test (methionine being the immediate precursor of homocysteine) may be required to demonstrate the metabolic abnormality in some cases. Deficiency of folic acid, pyridoxine and vitamin B12 (all cofactors in homocysteine metabolism) appear to exacerbate the underlying metabolic deficit. Treatment by dietary therapy, folate or pyridoxine may reduce vascular complications. ${ }^{46}$

Although atheroma commonly forms at the carotid bifurcation, it can also develop along the common carotid artery. Atheroma here is particularly common in patients who have received radiotherapy for laryngeal tumours. ${ }^{47}$ Cranial irradiation produces a radiation vasculopathy of the cerebral vessels. Endarterectomy of proximal cervical atheroma can be technically difficult if the common carotid origin is involved, necessitating alternative revascularisation techniques such as bypass procedures or angioplasty.

\section{MIGRAINE}

The number of strokes attributed to migraine varies from as few as $4 \%^{30}$ to as many as $20 \% .^{22}$ Before diagnosing migrainous stroke it is important to exclude other coexisting conditions. ${ }^{48}$ The overall lifetime prevalence of migraine is $10-$ $16 \%$ and for the majority of patients with migraine who have a stroke, migraine is not the cause. Ischaemic stroke can precipitate migraine in the elderly and a case has been made for investigating such patients for cerebrovascular disease. There are similar reports of 'symptomatic migraine' occurring in young patients with internal carotid artery dissection ${ }^{49}$ and it is probable that many 'migrainous strokes' in early series were, in fact, dissections.

Stroke can only be attributed to migraine if certain conditions are fulfilled ${ }^{50}$ :

- the ischaemic event develops in a patient who suffers migraine with aura (classical migraine)

- the provoking attack is identical to previous attacks

- the neurological deficit is not reversible after seven days

- investigations have excluded other causes.

Stroke cannot be blamed on migraine if there is a history of migraine without aura (common migraine) only.

Case-control studies reveal an excess of classical compared to common migraine (odds ratio 1.3 vs 0.8 ) in young stroke patients, and an increased susceptibility to stroke in young women with migraine, especially those who smoke, but not those who take oral contraceptives. ${ }^{51,52}$ The overall relative risk of stroke that migraine conveys is unknown but appears to be small.

Migrainous strokes typically involve the territory of the posterior cerebral arteries but not exclusively so (figure 3), and probably arises from prolonged arteriolar constriction. Small vessel thrombosis due to platelet activation also plays a role. Uncertainty in pathogenesis is reflected in uncertainty about optimum treatment; we ensure adequate codeine-based analgesia, give aspirin, and would add steroids and a calcium channel antagonist if initial measures prove inadequate. The risk of recurrent migrainous stroke was thought to be low but a third of patients in a recent survey had recurrent events. ${ }^{51}$ Whatever the future risk, future migraine prophylaxis is necessary. 


\section{Case report 2: Cardioembolic stroke with atrial septal defect and aneurysm}

A 33-year-old woman suddenly developed a right homonymous hemianopia. She had no vascular risk factors. Cardiovascular examination was normal. Neurological examination revealed the visual field deficit but no other signs. Aspirin was commenced. Unenhanced CT performed within 24 hours was normal. MRI revealed a left occipital infact. ECG and chest radiography were normal. There was no evidence of vertebral artery dissection on duplex ultrasound or MRA. Thrombophilia screen was negative.

Although her field defect gradually improved she continued to have discrete episodes of more pronounced right homonymous hemianopia with sensory disturbance of the right-sided limbs. She was anticoagulated with warfarin. Transthoracic echocardiography revealed an atrial septal aneurysm. Transoesophageal echocardiography confirmed an extensive atrial septal aneurysm and an interatrial septal defect (atrial septal defect or patent foramen ovale). Given the risk of lifelong anticoagulation with warfarin, the cardiac abnormalities were surgically repaired. The redundant atrial septum was excised and a large secundum atrial septal defect was closed. Warfarin was discontinued. She had no further cerebral ischaemic episodes.

\section{DRUGS}

Recreational drug abuse was not listed as a cause of young stroke in a British review in $1979^{53}$ and it was not identified as a precipitant of stroke in 60 young patients in Oxfordshire between 1978 and 1982. ${ }^{54}$ However it accounted for $10 \%$ of young stroke in Baltimore, US, from 1988 to $1989^{55}$ and appears as a leading cause of stroke in most contemporary series. Drug abuse increases the relative risk of stroke six-fold across all age groups and eleven-fold in people under 35 years. ${ }^{55}$

Cerebral infarction occurs with heroin, amphetamine and cocaine abuse, and abuse of over-the-counter sympathomimetics. The mechanism of ischaemia is predominantly one of obliterative arteritis due to immune complex deposition following prolonged challenges with foreign antigen. Incomplete solution of crushed oral preparations also generates an arteritic response in the brain and the lungs. The subsequent development of pulmonary arteriovenous fistulae promotes transpulmonary passage of even larger sized particles into the systemic circulation. Stroke onset is usually between six and 24 hours following drug administration. Necrotic cerebral infarction also arises indirectly in drug abusers through concomitant bacterial endocarditis or fungal infections with Nocardia or Aspergillus. ${ }^{56}$

\section{THROMBOPHILIAS}

Although thrombosis is usually triggered by an abnormal endovascular surface, primary abnormalities of the coagulation and fibrinolytic systems are also associated with venous and occasionally arterial thrombosis. The inherited thrombophilias (deficiencies of proteins $\mathrm{C}, \mathrm{S}$ and antithrombin) are relatively common $(1: 200$ to $1: 2000)$ in the heterozygous form ${ }^{57}$ but symptomatic deficiencies are less widespread (perhaps 1:36 000). ${ }^{58}$ Symptomatic episodes are usually venous thromboses of the calf or unusual sites such as the cerebral dural sinuses. Arterial thrombosis is less common and there may be overrepresentation of hereditary thrombophilias in young stroke series due to assay of these factors soon after the acute event. Protein $S$ levels in particular fall with acute complement activation thus persisting deficiency over the ensuing six months should be demonstrated for definitive diagnosis. Other prothrombotic states (polycythaemia, myeloproliferative disorders, thrombotic thrombocytopaenic purpura, hyperfibrinogenaemia, etc) also require exclusion.

\section{ANTIPHOSPHOLIPID ANTIBODIES AND LUPUS ANTICOAGULANT}

Lupus anticoagulant and anticardiolipin antibodies belong to a class of antibodies with activity against protein-phospholipid complexes. They are detected in $50 \%$ of patients with lupus and occur in other autoimmune disorders such as rheumatoid arthritis and giant cell arteritis. ${ }^{57,59}$ They are found in patients without evidence of collagen vascular disorders but with a history of recurrent arterial and venous thromboses, spontaneous abortions and livedo reticularis (the primary antiphospholipid [Sneddon's] syndrome). They are an independent risk factor for cerebral infarction ${ }^{60}$ and are an important cause of a false positive VDRL.

The mechanism of infarction in antiphospholipid syndromes and lupus was considered to be vasculitic. Current opinion, however, favours a primary thrombotic tendency within small arterioles. ${ }^{61}$ Spontaneous recanalisation of these thromboses gives rise to the multiple narrowings seen on angiography previously considered inflammatory. Additional cardioembolism (Liebmann Sachs endocarditis - which may only be diagnosed on transoesophageal echocardiography) and thrombotic thrombocytopenia are common causes of infarction in systemic lupus erythematosus. ${ }^{62}$ Treatment requires antiplatelet agents and/or anticoagulation according to the clinical picture. Immunosuppression using cyclophosphamide has been advocated for patients who fail to respond. Steroids used alone seem ineffective.

SYSTEMIC AND ISOLATED VASCULITIS OF THE CENTRAL NERVOUS SYSTEM Vasculitis can affect the central nervous system (CNS) as an isolated phenomenon (isolated angiitis of the CNS) or as part of a systemic necrotising vasculitis (eg, Wegener's, polyarteritis nodosa). ${ }^{63}$ A CNS vaculitis arising from the latter may occur in a previously diagnosed patient. If not, the associated features and peripheral haematological and immunological markers aid diagnosis. In addition, the predilection of polyarteritis for peripheral nerves (mononeuritis multiplex) allows readily available tissue for histology (sural nerve biopsy).

Other categories of arteritis include autoimmune disorders (rheumatoid arthritis, systemic lupus erythematosus, scleroderma, etc), infections (herpes zoster, cytomegalovirus, human immunodeficiency virus (HIV), tuberculosis, 


\section{Case report 3: Migrainous stroke}

For the previous 10 years a 35-year-old man had attacks of migraine twice anually. He developed one of his typical migraine attacks. Then his vision became blurred and over the next 12 hours he started bumping into things on his right hand side. The visual disturbance fluctuated in severity and he became progressively dysphasic and forgetful. His migrainous headache persisted.

Cardiovascular examination was normal. He was dysphasic and had a right homonymous hemianopia. Over the next week he developed fluctuating right pyramidal signs. MRI of the brain revealed infarction in the left occipital lobe, and repeat MRI after seven days showed extension of the infarct into the left temporal lobe (figure 3 ). Cerebral angiography showed pruning of the smaller vessels in the left parietooccipital region but no definite vasospasm. Cardiac and

haematological investigations were normal.

Aspirin and verapamil were commenced. When the pyramidal signs developed, steroid therapy (prednisolone $40 \mathrm{mg}$ daily) was started. He gradually improved and the prednisolone was tapered off.

Verapamil was replaced by propranolol for long-term prophylaxis.

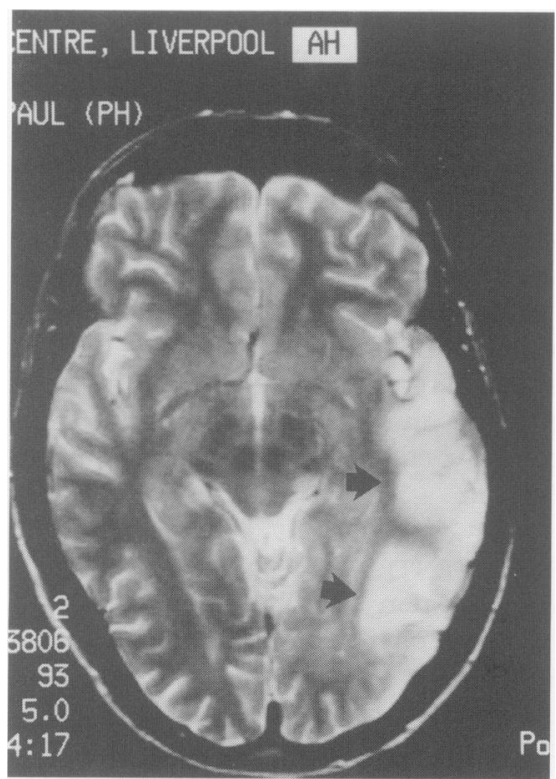

Figure 3 Axial T1-weighted MRI of the brain showing extensive infarction in the left temporal lobe and along the inferior surface of the left occipital lobe (arrows). The cause of this atypical distribution of cerebral infarction was severe migraine (Case 3 ) syphilis), neoplasia (lymphomas, hairy cell leukaemia, neoplastic angioendotheliosis), and drugs (cocaine, amphetamines, sympathomimetics). All arteritides due to infections are more severe in patients with concomitant HIV infection who also develop mycotic aneurysms and thrombotic noninfective endocarditis. Stroke accounts for $3 \%$ of the CNS features of acquired immunodeficiency syndrome. ${ }^{64}$ Meningovascular syphilis is characterised by headache, seizures and hemiplegia in the presence of positive serology. Zoster arteritis can result in a contralateral hemiparesis arising six to eight weeks after ophthalmic zoster.

Isolated angiitis of the CNS presents a diagnostic challenge. This rare disorder affects all age groups of both sexes. It presents acutely or subacutely as a focal or diffuse encephalopathy. Confusion (63\%), headache (59\%), hemiparesis $(44 \%)$ and drowsiness $(32 \%)$ are the most common features ${ }^{65}$ but transient ischaemic attacks, acute stroke and multi-infarct states are described. There are usually no symptoms outside the $\mathrm{CNS}$ other than vague malaise, weight loss or occasional fever (10-15\%). Left untreated, the condition carries a poor prognosis (90\% mortality within a year of diagnosis). ${ }^{65}$ Combination treatment with prednisolone and cyclophosphamide can be curative, especially in patients presenting with focal features. Presentation with a severe diffuse encephalopathy indicates a poor outcome.

There are usually no peripheral markers of isolated angiitis (normal erythrocyte sedimentation rate, negative autoantibody screens) but a mononuclear pleocytosis and mildly elevated protein may be found in the cerebrospinal fluid. The electroencephalogram is nonspecifically slow, and MRI shows multiple small hyperintensities on T2 images whose appearance is also nonspecific. Cerebral angiography shows multiple segmental narrowing of medium and small vessels in approximately $50 \%,{ }^{15,65}$ but similar appearances can arise from carcinomatous meningitis, radiation vasculopathy, or fibromuscular dysplasia. ${ }^{66}$ The diagnosis is secured by leptomeningeal and wedge cerebral biopsy (nondominant frontal lobe or temporal tip) which carries a risk of $0.5-2 \%$ of focal deficit or death. The benefit of histological diagnosis, given a potentially treatable condition, outweighs the risk of biopsy in a suspected case and there is no place for empirical treatment given that steroids and cyclophosphamide administration might last for 12 months or more. The decision to biopsy must be made on an individual basis in consultation with the patient's family. We would tend to proceed to biopsy if the clinical state is deteriorating and the angiogram is negative or unhelpful.

\section{PREGNANCY}

Historically, pregnancy has been considered a risk factor for ischaemic stroke. Early studies suggested an incidence of one stroke per 2000 pregnancies. ${ }^{67}$ Difficulties with population bias and incorrect diagnosis prior to the CT era account for much of the over-estimation. Recent studies have suggested an incidence of 1 in 10000-20000 pregnancies and cohort studies suggest little difference in the stroke rate between pregnant women and nonpregnant women of childbearing age. ${ }^{68}$ There appears to be a definite association of cerebral venous thrombosis with pregnancy and the puerperium. ${ }^{69}$

Pregnancy-related ischaemic strokes usually occur during the third trimester and puerperium. In addition to the usual risk factors, pregnancy brings its own specific conditions. Eclampsia is associated with cerebral haemorrhage but surges in blood pressure against a background of hypertension might also precipitate infarction. Other causes include choriocarcinoma, paradoxical embolism, hypotension and postpartum cardiomyopathy. The British Neurological Surveillance Unit aims to answer some of the unresolved dilemmas surrounding pregnancy-related stroke. ${ }^{68}$

\section{GENETIC DISORDERS}

It is clear that genetic factors influence disorders such as diabetes mellitus, hypertension and hyperlipidaemias, all of which predispose to cerebral infarction. Recently a single gene disorder directly responsible for ischaemic stroke has been described. The gene for cerebral autosomal dominant arteriopathy with subcortical infarcts and leucoencephalopathy (CADASIL) localises to chromosome $19,{ }^{70}$ which also hosts the gene for familial hemiplegic migraine. CADASIL presents from the third decade with discrete stroke or transient ischaemic attack then develops a phase of progressive neurological disability, pseudobulbar palsy and dementia. MRI reveals multiple small infarcts in the deep white matter which have been confirmed at autopsy. Although only a few families have so far been described, the identification of CADASIL illustrates the existence of primary genetic disorders directly responsible for cerebral vascular disease in the young.

Stroke is seen as a manifestation of other inherited disorders. Mitochondrial 
myopathy, encephalopathy, lactic acidosis and stroke-like episodes (MELAS) is a mitochondrial cytopathy diagnosed by increased lactate levels in blood and cerebrospinal fluid, muscle biopsy (for ragged red fibres) and mitochondrial DNA analysis. As with other mitochondrial cytopathies, father to son transmission is impossible since all mitochondria are derived from the ovum.

Ehlers Danlos syndrome type IV (autosomal dominant), Marfan's syndrome (autosomal dominant), osteogenesis imperfecta (autosomal dominant [types I, II, IV] and recessive [type III]), and pseudoxanthoma elasticum (autosomal dominant and recessive forms described) are all causes of cervical artery dissection. The latter is also associated with intracranial arterial occlusive disease, as is neurofibromatosis type $1 .^{71}$ Fabry's disease (X-linked recessive inheritance) is a lysosomal storage disorder characterised by angiokeratoma corporis diffusum - dark red papules found on the lower trunk, perineum and thighs. Deficiency of $\alpha$-galactosidase leads to accumulation of trihexosyl ceramide in blood vessels. Patients die in the fourth and fifth decades from cerebrovascular, cardiovascular or renal disease.

\section{Prognosis}

Prognosis in young stroke reflects the underlying cause and the extent of initial neurological damage. The greater collateral reserve in the young adult brain limits the initial size of infarction and there is greater scope for functional recovery than in the elderly.

Initial mortality in young ischaemic stroke is approximately $2-7 \%, 42,72$ and occurs predominantly in those with large vessel occlusive disease. Overall, the risk of recurrent stroke is $1-3 \%$ per annum. ${ }^{73,74}$ Premature atherosclerosis is associated with a high chance of future morbidity (myocardial infarction, peripheral vascular disease, sudden death) and patients in this category have twice the risk of future vascular events than other young stroke survivors. This necessitates an aggressive approach to risk factor modification. In contrast, patients with stroke in whom full investigation fails to elucidate a cause have a low risk of recurrence $\left(0.5-1 \%\right.$ per annum) ${ }^{22,73,74}$

Amongst survivors of young stroke, $75 \%$ have little or no handicap, up to $55 \%$ of patients suffer significant depression, $50 \%$ report significantly impaired quality of life and only $40 \%$ return to work. ${ }^{75,76}$ Although $90 \%$ of those who receive physiotherapy, occupational therapy and speech therapy feel they benefit, only $40 \%$ of young stroke patients receive these measures. ${ }^{75} \mathrm{~A}$ recent UK survey found young stroke patients to be receiving as little as one hour of speech and physiotherapy weekly whilst in hospital. ${ }^{77}$ The role of ancillary therapists to offer psychological counselling, aid in the home and in the workplace, must not be underestimated.

\section{Conclusion}

Our perception of the principal causes of ischaemic stroke has changed considerably over the last 15 years. New imaging modalities allow us to appreciate conditions such as arterial dissection which were previously greatly underrecognised. Advances in haematology and immunology promote greater awareness of the inherited and acquired thrombophilias. Recent advances in genetics have enabled the identification of a single gene disorder which manifests as stroke and further genetic defects are likely to be identified. Social changes such as the increasingly widespread use of recreational drugs are reflected in the greater representation of drug abuse as a cause of stroke in the young.

It is no longer sufficient merely to demonstrate cerebral infarction as the cause of the neurological deficit in the young stroke patient. The chances of finding an underlying cause are rising as technology and knowledge progress. In addition, the opportunities for therapeutic intervention are many and should not be missed, given the life expectancy of this age group.

1 Department of Health. Stroke rehabilitation. Effective Health Care 1992; 2: 1 - 11.

2 Shriver ME, Prockop LD. The economic approach to the stroke work-up. Curr Opin Neurol Neurosurg 1993; 6: 74-7.

3 Bamford J, Sandercock P, Dennis M, Burn J, Bamford J, Sandercock P, Dennis $M$, Burn J, Warlow C. A prospective study of acute cerebrovscular disease in the community: the Oxfordshire Community Stroke Project; 1981-86. 2. Incidence, case fatality rates and overall outcome at one year of cerebral infarction, primary intracerebral and subarachnoid haemorrhage. $\mathcal{F}$.
4 Lidegaard O, Sol M, Anderson MVN. Cerebral thromboembolism among young women and men in Denmark from 1977 to 1982 . Stroke 1986; 17: $670-5$.

5 Mettinger KL, Södeström CE, Allander E. Epidemiology of acute cerebrovascular disease from 1973 to 1977: incidence and mortality from 1973 to 1977: incidence

6 Leno C, Berciano J, Combarros O, et al. A

Leno C, Berciano J, Combarros $\mathrm{O}$, et al. A Cantabria, Spain. Stroke 1993; 24: 792-5.
7 Hankey GJ, Warlow CP. Symptomatic carotid ischaemic events: safest and most cost effective way of selecting patients for angiography, before carotid endarterectomy. $B M F$ 1990; 300: $1485-$ 91.

8 Martin PJ, Enevoldson TP. Classic diseases revisited: cerebral venous thrombosis. Postgrad Med f 1996; 72: $72-6$.

9 Biller J, Johnson M, Adams HP Jr, Kerber R Butler M, Toffol G. Echocardiographic evaluation of young adults with non-hemorrhagic cerebral infarction. Stroke 1986; 17: 608-12. 
10 Adams HP Jr, Love BB. Transesophogeal echocardiography in the evaluation of young adults with ischemic stroke: promises and concerns. Cerebrovasc Dis 1995; 5: 323-7.

11 Müllges W, Ringelstein EB, Leibold M. Noninvasive diagnosis of internal carotid artery dissections. F Neurol Neurosurg Psychiatry 1992; 55: $98-104$.

12 Young G, Humphrey PRD, Shaw MDM, Smith ETS. A comparison of magnetic resonance angiography, duplex ultrasound and digital subtraction angiography in the assessment of extracranial internal carotid artery stenosis. $f$ extracranial internal carotid artery stenosis. $\mathcal{F}$

13 Caplan LR, Wolpert SM. Angiography in patients with occlusive cerebrovascular disease: views of a stroke neurologist and neuroradiologist. Am $\mathcal{f}$ Neuroradiol 1991; 12: 593-601

14 Ross JS, Masaryk TJ, Modic MT, Ruggier PM Haacke EM, Selman WK. Intracranial aneurysms: evaluation by magnetic resonance angiography. $A f R$ 1990; 155: 159-65.

15 Sellar RJ. Imaging blood vessels of the head and neck. F Neurol Neurosurg Psychiatry 1995; 59: 225-37.

16 Ringelstein EB, Biniek R, Weiller C, Ammeling B, Nolte PN, Thron A. Type and extent of $\mathrm{B}$, Nolte $\mathrm{PN}$, Thron A. Type and extent of come in early and delayed middle cerebral artery come in early and delayed midde cerebral

17 Markus H. Transcranial Doppler detection of circulating cerebral emboli. Stroke 1993; 24 1246-50.

18 Teague SM, Sharma MK. Detection of paradoxical echo-contrast embolization by transcranial Doppler ultrasound. Stroke 1991; 22: 740 5.

19 Schievink WI, Prakash UBS, Piepgras DG, Mokri B. Alpha-1-antitrypsin deficiency in intracranial aneurysms and cervical artery dissection. Lancet 1994; 343: 452-3.

20 Giroud M, Fayolle H, André N, et al. Incidence of internal carotid artery dissection in the community of Dijon. $₹$ Neurol Neurosurg Psychiatry 1995; 58: 1443 .

21 Lisovoski F, Rousseaux P. Cerebral infarction in young people. A study of 148 patients with early cerebral angiography. If Neurol Neurosurg Psychiatry 1991; 54: 576-9.

22 Bogousslavsky J, Pierre P. Ischemic stroke in patients under age 45. Neurol Clin 1992; 10 $113-24$.

23 Biousse V, D'Aglejan-Chatillon J, Touboul P-J, Amarenco P, Bousser M-G. Time course of symptoms in extracranial carotid artery dissections. A series of 80 patients. Stroke 1995; 26: 235-9.

24 Schievink WI, Mokri B, O'Fallon WM. Recurrent spontaneous cervical artery dissection. $N$ rent spontaneous cervical artery

25 Eljamel MSM, Humphrey PRD, Shaw MDM Dissection of the cervical internal carotid artery:
the role of Doppler/duplex studies and conserthe role of Doppler/duplex studies and conservative mangement.

26 Hoffman M, Sacco RL, Chan S, Mohr JP. Noninvasive detection of vertebral artery dissection. Stroke 1993; 24: 815-9.

27 Mokoi B, Sundt TM, Houser OW, Piepgras DG. Spontaneous dissection of the cervical internal

28 Caplan L, Tettenborn B. Vertebrobasilar occlusive disease: spontaneous dissection of extracranial and intracranial posterior circulation arteries. Cerebrovasc Dis 1992; 2: 256-65.

29 Adams HP Jr, Butler MJ, Biller J, Toffol J. Nonhemorrhagic cerebral infarction in young adults. Arch Neurol 1986; 43: 793-6.

30 Adams HP Jr, Kappelle J, Biller J, et al. Ischemic stroke in young adults: experience in 329 patients enrolled in the Iowa Registry of Stroke in Young Adults. Arch Neurol 1995; 52: $491-5$.

31 Hagen PT, Scholz DG, Edwards WD. Incidence and size of patent foramen ovale during the first 10 decades of life: an autopsy study of 965 normal hearts. Mayo Clin Proc 1984; 59: $17-20$.
32 Carolei A, Marini C, Ferranti E, Frontoni M Prencipe $M$, Fieschi $C$ and the National Research Council Study Group. A prospective study of cerebral ischaemia in the young: analysi of pathogenic determinants. Stroke 1993; 24 $362-7$.

33 Bevan H, Sharma K, Bradley W. Stroke in young adults. Stroke 1990; 21: $382-6$.

34 Markiewicz W, Stoner J, London E, Hunt SA Copp RL. Mitral valve prolapse in one hundred presumably healthy young females. Circulation presumably healthy

35 Lechat P, Mas JL, Lescault G, et al. Prevalence of patent foramen ovale in patients with strokes. $N$ Engl F Med 1988; 318: $1148-52$.

36 Gates PC, Barnett HJM, Silver MD. Cardiogenic stroke. In: Barnett HJM, Mohr JP, Stein BM, Yatsu FM, eds. Stroke: pathophysiology, Livingstone, 1986; pp 1085-109.

37 Hart RG, Easton JD. Mitral valve prolapse and cerebral infarction. Stroke 1982; 13: 429-31.

38 Hofman T, Kasper W, Meinertz T, Geibel A, Just $H$. Echocardiographic evaluation of patients with clinically suspected arterial emboli. Lancet 1990; 336: 1421-4.

39 Pearson AC, Nagelhoot D, Castello R, Gomez CR, Labovitz AJ. Atrial septal aneurysm and stroke. A transesophageal echocardiographic
study. F Am Coll Cardiol 1991; 18: 1223-9.

40 DiTullio M, Sacco RL, Venketa N, Sherman D, Mohr JP, Homma S. Comparison of diagnostic techniques for the detection of a patent foramen ovale in stroke patients. Stroke 1993; 24: 1020 4.

41 Cerebral Embolism Study Group. Immediate anticoagulation of embolic stroke: brain haemorrhage and management options. Stroke 1984; 15: 779-89.

42 Bogousslavsky J, Regli F. Ischemic stroke in adults younger than 30 years of age. Arch Neurol 1987; 44: 479-82.

43 Perry IJ, Refsum H, Morris RW, Ebrahim SB Ueland PM, Shaper AG. Prospective study of serum total homocysteine concentration and ris of stroke in middle-aged British men. Lance 1995; 346: 1395-8.

44 Selhub J, Jacques PF, Bostom AG, et al. Association between plasma homocysteine concentrations and extracranial carotid artery stenosis. $N$ Engl f Med 1995; 332: 286-91.

45 Verhoef P, Hennekens CH, Malinow R, Kok FJ, Willett WC, Stampfer M. A prospective study of plasma homocyst(e)ine

46 Stampfer MJ Malinow MR Can lowering homocysteine levels reduce cardiovascular risk? homocysteine levels reduce cardio

47 Murros KE, Toole JF. The effect of radiation on carotid arteries. Arch Neurol 1989; 46: 449-55.

48 Shuaib A. Stroke from other etiologies masquerading as migraine stroke. Stroke 1991; 22: $1068-74$

49 Olesen J, Friberg L, Olsen TS, Andersen AR, Lassen NA, Hansen PE, Karle A. Ischaemiainduced (symptomatic) migraine attacks may be more frequent than migraine-induced insults. Brain 1993; 116: 187-202.

50 International Headache Society. Classification and diagnostic criteria for headache disorders, cranial neuralgias, and facial pain. Cephalalgia 1988; 8: 27.

51 Rothrock J, North J, Madden K, Lyden P, Fleck $\mathrm{P}$, Dittrich $\mathrm{H}$. Migraine and migrainous stroke: risk factors and prognosis. Neurology 1993; 43: 2473-6.

52 Tzourio C, Iglesias S, Hubert J-B, et al. Migraine and risk of ischaemic stroke: a case control study. $B M \mathcal{F}$ 1993; 307: 289-92.

53 Warlow C. The young stroke. Br 7 Hosp $\mathrm{Med}$ 1979; 20: 252-9.

54 Hilton-Jones D, Warlow CP. The causes of 43.
55 Sloan MA, Kittner SJ, Rigamomti D, Price TR Occurrence of stroke associated with use/abuse of drugs. Neurology 1991; 41: 1358-64.

56 Caplan LR. Nonatherosclerotic ischaemia. In Caplan LR. Stroke - a clinical approach. Boston: Butterworth Heinemann, 1993; pp 299-348.

57 Greaves M. Coagulation abnormalities and cerebral infarction. F Neurol Neurosurg Psychiatry 1993; 56: 433-9.

58 Gladson CL, Sharrer I, Hach V, Beck KH, Griffin JH. The frequency of type 1 heterozygous protein $\mathrm{C}$ deficiency in 141 unrelated young protein $C$ deficiency in 141 unrelated young patients with venous 1988 ; 59: $18-22$.

59 Futrell N. Inflammatory vascular disorders: diagnosis and treatment in ischemic stroke. Cur Opin Neurol 1995; 8: 55-61.

60 The Antiphospholipid Antibodies Group. Anticardiolipin antibodies are an independent risk factor for first ischemic stroke. Neurology 1993; 43: $2069-73$.

$61 \mathrm{Lie} \mathrm{JT}$. Vasculitis in the antiphospholipid syndrome: culprit or consort? F Rheumatol 1994; 21: 397-8.

62 Devinsky $\mathrm{O}$, Petito $\mathrm{CK}$, Alonso DR Clinical and neuropathological findings in systemic lupus erythematosus. The role of vasculitis, heart emboli and thrombotic thrombocytopenic purpura. Ann Neurol 1988; 23: $380-4$.

63 Moore PM, Cupps TR. Neurological complications of vasculitis. Ann Neurol 1983; 14: 155-67.

64 Levy RM, Bredesen BE, Rosenblum ML Neurological manifestations of the acquired immunodeficiency syndrome (AIDS): experience at UCSF and review of the literature. Neurosurg 1985; 62: 475-95.

65 Hankey GJ. Isolated angiitis/angiopathy of the central nervous system. Cerebrovasc Dis 1991; 1: 2-15.

66 Alhalabi M, Moore PM. Serial angiography in isolated angiitis of the central nervous system. Neurology 1994; 44: 1221-6.

67 Wiebers DO, Whisnant JP. The incidence of stroke among pregnant women in Rochester Minn, 1955-1979. JAMA 1985; 254: 3055-7.

68 Grosset DG, Ebrahim S, Bone I, Warlow C. Stroke in pregnancy and the puerperium: what magnitude of risk? J Neurol Neurosurg Psychiatry 1995; 58: 129-31.

69 Ameri A, Bousser M-G. Cerebral venous thrombosis. Neurol Clin 1992; 10: 87-111.

70 Tournier-Lasserve E, Iba-Zizen M-T, Romero N, Bousser M-G. Autosomal dominant syndrome with stroke-like episodes and leukoencephalopathy. Stroke 1991; 22: 1297-302.

71 Schievink WI, Michels VV, Piepgras DG Neurovascular complications of heritable connective tissue disorders. Stroke 1994; 25: 889903.

72 Marshall J. The cause and prognosis of strokes in people under 50 years. $f$ Neurol Sci 1982; 53: 473-88.

73 Lanzino G, Andreoli LG, Di Pasquale G, et al. Etiopathogenesis and prognosis of cerebral ischaemia in young adults. A survey of 155 treated patients. Acta Neurol Scand 1991; 84: 321-5.

74 Hindfelt $B$, Nilsson $O$. The prognosis of ischaemic stroke in young adults. Acta Neurol Scand 1977; 55: 123-30.

75 Kappelle LJ, Adams HP Jr, Heffner NL, Torner JC, Gomez F, Biller J. Prognosis of young adults with ischemic stroke. A long-term follow-up
study assessing recurrent vascular events and study assessing recurrent vascular events and
functional outcome in the Iowa registry of stroke in young adults. Stroke 1994; 25: 1360-5.

76 Frederico F, Calvario T, Di Turi N, Paradiso F. Ischaemic cerebral infarction in young adults. Acta Neurol Ital 1990; 12: 101-8.

77 Pollock SS. Audit of hospital coding and investigation of patients with stroke under $65 . \mathcal{F}$ Neurol Neurosurg Psychiatry 1996; 60: 119. 